Dossiê Processos de CONVersão Religiosa 



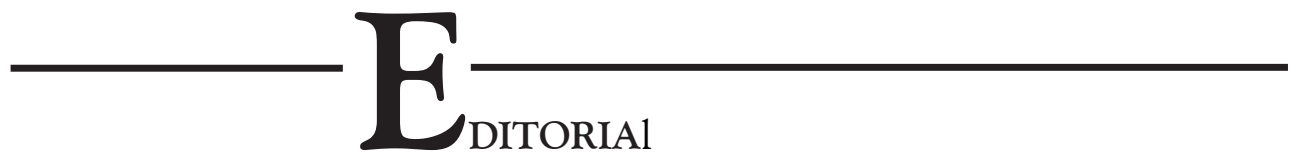

\section{Processos De CONVERSÃo Religiosa}

Cesar Pinheiro Teixeira

Universidade de Vila Velha

Vila Velha - ES - Brasil

https://orcid.org/0000-0002-8517-0281

Christina Vital-da-Cunha Universidade Federal Fluminense Niterói - RJ - Brasil https://orcid.org/0000-0003-4867-1500

Diogo Silva Corrêa Universidade de Vila Velha

Vila Velha - ES - Brasil https://orcid.org/0000-0002-5932-7599

Livia Reis Universidade Federal do Rio de Janeiro Rio de Janeiro - RJ - Brasil https://orcid.org/0000-0003-3696-762X

Há pouco mais de 20 anos, a socióloga francesa Danièle Hervieu-Leger ([1999]2008) nos alertava sobre a existência de uma modernidade religiosa, desinstitucionalizada e individualista, que poderia ser capturada com base em dois grandes 
personagens típico-ideais: o peregrino - o produtor de bricolagens religiosas - e o convertido - aquele que escolhe por si integrar-se à outra orientação religiosa. Enquanto a figura do peregrino traz à tona a temática da continuidade e da articulação de diferenças, o convertido aparece como o personagem da ruptura - ambos dotados da autonomia pressuposta pela forma de vida baseada no individualismo moderno liberal. Por mais antigo e clássico que seja o tema da conversão como metanoia desde o texto bíblico na narração de Paulo a caminho de Damasco até Agostinho em Confissões -, Hervieu-Leger chama atenção para a dimensão sócio-histórica do fenômeno, apontando para a singularidade e os contornos que ele assume no mundo contemporâneo.

De uma perspectiva geral, portanto, a ideia de uma conversão religiosa na modernidade produz certo fascínio sobre as pessoas justamente porque ela se tornou um arquétipo da mudança de vida (Rambo 2003). A conversão religiosa tematiza algo caro ao mundo moderno: uma espécie de mobilidade existencial voluntariamente dirigida, deixando sempre em aberto a presença potencial de outra vida possível (Duarte e Giumbelli 1995). A conversão coloca no horizonte do homem moderno a possibilidade de tornar-se outro, isto é, de afastar-se de um conjunto axiomático de valores ou de determinada visão de mundo e engajar-se em outra. Ela indica que, em princípio, toda e qualquer pessoa pode romper com o seu passado, exilar-se de sua cultura de origem, transitar para outra comunidade de pertencimento e tornar-se, enfim, um novo sujeito, uma nova pessoa (liberta, emancipada, salva, em suma, diferente etc.). Assim, a conversão religiosa está diretamente associada a um conjunto de vetores que Charles Taylor (1997) denominou como as fontes do self no mundo moderno.

Não é por acaso que, neste contexto, a conversão religiosa se torna um persistente objeto de reflexão nas ciências sociais, uma espécie de leitmotif dos debates sobre religião e examinada com base em diversos enquadramentos teóricos. Nos anos 1960 e 1970, por exemplo, uma perspectiva muito influente em trabalhos britânicos e norte-americanos (Lofland \& Stark 1965; Horton 1971; Heirich 1977) toma inicialmente a conversão religiosa como uma categoria analítica. Nesse caso, parte-se do princípio de que ela seria a expressão direta de um processo concreto: as experiências de transformação nas estruturas cognitivas do self. Esse tipo de abordagem foi severamente criticado, especialmente por conta do pressuposto de que, se assim concebida, a conversão religiosa poderia ser tomada como uma coisa, como um objeto passível de ser isolado e examinado em si mesmo (Comaroff \& Comaroff, 1991). A crítica aponta justamente para a relevância dos contextos (sociais, culturais, políticos) nos quais os processos de conversão ocorrem e a como, em certa medida, as "transformações de si" estão bastante conectadas com eles, isto é, apontam para o que é reconhecido como uma continuidade das estruturas para além de aparentes rupturas.

Joel Robbins (2003) complexifica o debate ao questionar a própria perspectiva antropológica, à qual se refere como sendo, em geral, uma ciência da continuidade (ibidem:222). Assim, segundo Robbins, alguns paradoxos produzidos pelo contexto 
de globalização do pentecostalismo tornariam evidente certos limites da perspectiva da continuidade. Desse modo, para compreender a expansão global do pentecostalismo, seria necessário desenvolver outra perspectiva analítica, que leve a sério as mudanças culturais e a descontinuidade existencial produzida pelos processos de conversão religiosa, uma antropologia da ruptura, portanto. Por outro lado, Engelke (2004) procura equilibrar o debate argumentando que o que está em jogo não é necessariamente a substituição de um paradigma da continuidade por um da ruptura, mas a construção de uma articulação entre os dois - embora concorde com Robbins e admita que a perspectiva da descontinuidade mereça mais atenção dos analistas que se debruçam sobre o tema.

No Brasil, reflexões contínuas sobre conversão religiosa ganharam expressão a partir dos anos 1980, impulsionadas pelo significativo crescimento pentecostal em um contexto marcado pela presença do catolicismo e das religiões de matriz afro brasileiras (Novaes 1985; Contins 1995; Birman 1996; Mafra 2002; Reinhardt 2006). Birman (ibidem), por exemplo, propõe priorizar o foco nos contextos de passagem entre diferentes sistemas simbólicos em detrimento de uma análise mais detida nos processos individuais. Segundo a autora, o foco na elaboração subjetiva levaria menos em conta o contexto social e religioso em que estaria inserida, perdendo de vista as zonas cinzentas produzidas pela interação. Mafra (ibidem) reconhece que esse tipo de abordagem abre a possibilidade de se considerar zonas de troca e negociação, mas se equivoca ao tomar como dado o agenciamento do indivíduo nesses processos de bricolagem e sincretismo. Além disso, a antropóloga argumenta ser arriscado ignorar que, nesses contextos, a conversão se torna uma categoria nativa importante visto que parte dos atores se reconhece envolvida na produção de uma transformação íntima e de ruptura. Campos e Reesink (2011:220) propõem que as duas dimensões da conversão (como categoria analítica e como categoria nativa) devem ser reconectadas analiticamente, uma vez que os processos de conversão só poderiam ser bem compreendidos ao se radicalizar a articulação entre as categorias do nativo e as do antropólogo.

O interesse de Mafra recaía sobre o que chamou de conversão minimalista. Esta pode ser caracterizada como um processo de trocas e negociações, de continuidades e rupturas, operados ativamente pelos próprios atores. De acordo com a autora, "não é mais tanto o pastor ou o corpo de fiéis - a congregação - que ensina e guia de perto as opções abertas para o novo converso, mas ele mesmo vai adequando sua nova postura até, como dizem, se 'sentir bem'” (ibidem:120). Nesse sentido, a abordagem de Mafra se aproxima muito das considerações de Engelke sobre a construção de uma mirada que contemple tanto as continuidades quanto as rupturas. $\mathrm{O}$ importante, portanto, seria não tomar a continuidade como algo dado, mas jogar luz sobre as entranhas das zonas cinzentas, compreendendo como os atores se movem entre elas. Teixeira (2016), por exemplo, argumenta que as continuidades e as rupturas, no caso da conversão pentecostal nos chamados centros de recuperação evangélicos, são reguladas por uma gramática moral do testemunho que delimita certo campo de 
possibilidades dentro do qual os atores podem lidar com transformações e permanências, compondo, desse modo, seus testemunhos e seus processos de conversão. Nesses contextos, converter-se significa aprender a operar corretamente tal gramática.

O debate sobre a conversão se estende para além das discussões sobre modernidade e globalização e das discussões sobre trânsito religioso. No Brasil, há variadas matrizes de reflexão que reelaboram a discussão a partir de outros enquadramentos empíricos, por exemplo: gênero e sexualidade (Machado 2013; Natividade 2008; Lopes 2017), a produção de subjetividades democráticas e a questão da exemplaridade (Dullo 2013), a produção de sujeitos orientados pela "teologia da prosperidade" (Mariano 1995; Mariz 1995; Oro 2003; Mesquita 2003; Lima 2008), instituições de privação de liberdade (Scheliga 2000; Dias 2008; Lobo 2009; Gusmão 2011), comunidades terapêuticas (Ribeiro e Minayo 2018; Teixeira e Brandão 2019; Targino e Mesquita 2020) e a pobreza urbana (Mariz 1991; Rolim 1995; Rivera 2016). Em relação a este último caso, uma vez que a "onda pentecostal" (Freston 1994) ocorreu de forma muito desigual entre as diferentes classes sociais brasileiras e concentrou-se, especialmente, nos estratos mais pobres da população (Mariano 2005; 2013:12; Vital da Cunha 2018), tais autores mobilizam variáveis sociológicas no intuito de explicar a razão pela qual "é nas áreas pobres que as igrejas pentecostais se alastram com maior velocidade" (Novaes 1998:9).

A primeira década do século XXI consolida uma nova dimensão da discussão que se relaciona diretamente com o contexto de "violência urbana" (Machado da Silva 2010). Essa tendência já tinha sido iniciada nos anos 1990, com base em trabalhos como os de Mafra (1998) e de Zaluar (1997) e de alguns de seus ex-alunos (ver Lins e Silva 1990). Nos anos 2000, surge uma série de pesquisas que procuram destrinchar melhor as complexas relações de aproximação e distanciamento entre o chamado "mundo do crime" (ver Feltran 2005) e as igrejas evangélicas (Côrtes 2007, 2017; Teixeira 2008, 2011, 2013; Vital Da Cunha 2008, 2014, 2015; Mesquita 2012; Birman e Machado 2011; Machado 2014; Abumanssur 2014; Corrêa 2015; Silva 2015). De maneira geral, esses autores apresentam como a contiguidade espacial entre crime e evangélicos se traduz em potenciais conflitos e dissonâncias, mas também numa paradoxal manutenção de diferenças aliadas a intersecções entre os dois mundos sociais.

No debate da religião e violência, Teixeira (2011) mostra de que maneiras as experiências de rompimento de ex-traficantes com o "mundo do crime", relacionadas à conversão religiosa, alimentam-se do mesmo processo que o constrói, o processo de sujeição criminal (Misse 1999), eixo central da construção social do criminoso, especialmente no Brasil. Vital da Cunha (2015), por outro lado, mostra em detalhes como se dá a expansão de uma gramática pentecostal em direção ao "mundo do crime", através do personagem mais característico dessa nova forma de experimentação do sagrado em contextos de "violência urbana", o traficante evangélico. Corrêa (2015), por sua vez, ao analisar o complexo entrelaçamento entre o "mundo do crime" e o 
"mundo evangélico", com base em uma sociologia em escala individual, mostra em detalhes como a conversão religiosa pode nos ajudar a construir uma perspectiva pragmática sobre o self, propondo, assim, sistematizá-la em uma sociologia dos problemas íntimos. Côrtes (2012) explora a ideia de que a conversão pode ser pensada a partir de um enquadramento mais amplo, como um, dentre outros, mecanismos de governamentalidade relativos a personagens considerados "estranhos", "inadequados", "desviantes" de forma geral. Machado (2014) descreve um complexo dispositivo pentecostal que captura e atribui sentido ao sofrimento daqueles amplamente considerados algozes da "violência urbana", os bandidos, e, ao mesmo tempo, reconfigura suas subjetividades com base em uma série de continuidades com o "mundo do crime", relativas à fama e ao poder.

Neste dossiê, convidamos à reflexão sobre processos de conversão em suas dimensões sensoriais, estéticas e políticas. A categoria conversão como metanoia ou reorientação da alma tem uma longa trajetória na filosofia e na teologia. Como vimos, no âmbito dos estudos de sociologia e antropologia, análises sobre conversão vêm enfatizando a complexidade deste momento de transformação em termos de seus sentidos, mediações, performances e narrativas. $O$ conjunto complexo de reflexões propostas neste campo aponta para a existência de processos que, como tais, se estendem ao longo de períodos, às vezes, indeterminados e cheios de contradições. Uma das perguntas que nos provocou à proposição deste dossiê é se, finda a segunda década do século XXI, em um Brasil no qual o pentecostalismo continua a crescer, haveria novas matrizes de reflexão sobre a conversão religiosa. Quais tendências sobre a paisagem religiosa no país e transnacionalmente podemos vislumbrar através das pesquisas sobre conversão? Quais dimensões sensoriais (ao mesmo tempo corpóreas e emocionais) são experimentadas pelos sujeitos e quais as mediações exercidas por humanos e não humanos nesses processos?

Para contribuir nesse debate, contamos com seis artigos cujas reflexões sobre conversões recaem sob diferentes perspectivas, revelando pontos de contato entre mídia, cultura, violência e transnacionalidade religiosa. Em todos os artigos, etnografias finas, algumas de longa duração, destacam potentes narrativas sobre a conversão na forma de testemunhos e catarses pontuais. No artigo de abertura, intitulado "O juízo da fama: moralidades e emoções nas narrativas testemunhas do mundo artístico evangélico", Raphael Bispo investiga a relação entre religiosidades evangélicas e o mundo artístico brasileiro contemporâneo. Aspectos relativos à indústria cultural e ao universo gospel são revelados e analisados pelo autor através de testemunhos de conversão de artistas famosos e que compõem a cultura popular brasileira através de marcos da antropologia das emoções e das moralidades. O autor destaca em sua análise crivos sociais revelados sob a forma de juízos sobre a espetacularização das trajetórias desses artistas elaboradas pelos próprios. Esses juízos da fama possuem enredo e sequência clara de acontecimentos divididos em atos discursivos densamente analisados pelo autor ao longo do artigo. 
Em "A relacionalidade da ruptura: conversão e parentesco espiritual em Gana", Bruno Reinhardt, por meio de uma abordagem crítica da antropologia do cristianismo, reflete sobre a conversão religiosa enfatizando seu caráter não linear e as diferentes composições existentes nesse processo. As reflexões se baseiam em uma etnografia realizada em início dos anos 2010 na Lighthouse Chapel International (LCI), na cidade de Acra (Gana). As situações testemunhais, o forte trabalho ético requerido nessas situações, são exploradas com vistas a retomar a pergunta inicialmente motivadora da análise: quem e como é um cristão e como o cristianismo produz mundos. Dessa forma, observa a dinâmica que envolve o fazer cristão em seu campo de estudo destacando o "parentesco espiritual" como uma noção fundamental para a formação desses seres convertidos, para o entendimento do "trabalho de conversão" que sustenta a promessa de um novo nascimento.

No terceiro artigo do dossiê, intitulado "Eu digo que sou católica e dou passe': sobre dádiva e conversão em um centro terapêutico espírita no sul do Brasil", de Waleska Aureliano, a noção de conversão assume conotação distinta daquela presente nos demais artigos deste dossiê. Através de etnografia realizada entre 2009 e 2010 no Centro de Apoio ao Paciente com Câncer (CAPC), um espaço terapêutico espírita na cidade de Florianópolis, a autora analisa o processo de passagem da situação de pacientes a voluntários dessa instituição como conversões terapêuticas. Nesses casos, salienta, as pessoas não se reconhecem necessariamente como espíritas, mas assumem práticas e uma visão de si informadas pelo kardecismo, além de exercerem papel significativo nos rituais do centro tal como a realização de passes durante as sessões. Dessa forma, Waleska Aureliano busca refletir sobre a diversidade e plasticidade das filiações e identificações religiosas expressas pelos voluntários acompanhados pela pesquisadora durante o campo.

Em "Conjugalidade e racionalidade neoliberal na Igreja Universal: a conversão do homo economicus em família-empresa e a submissão da mulher", Valéria Marchesi, Pablo Ornelas Rosa e Paulo Edgar Resende discutem o tema da conversão e da subjetivação de mulheres na Igreja Universal do Reino de Deus tendo como base empírica as liturgias de "Terapia do Amor", em templos em Vitória (ES) e São Paulo (SP). Argumentam que tecnologias de poder propostas pela igreja produzem um assujeitamento dos fiéis em bases que põem em contato valores religiosos, tradicionais da sociedade brasileira e do neoconservadorismo hodierno, assim como econômicos. Neste sentido, a família patriarcal iurdiana se assentaria não só na monogamia e na parentalidade heterossexual, mas na conformação de um núcleo empreendedor afinada aos ideais neoliberais.

Em "O pastor como hiperconvertido: uma etnografia da constituição do líder pentecostal", Cleonardo Mauricio-Junior apresenta uma perspectiva inovadora em torno dos líderes vocacionados para o exercício de ministração da Bíblia. Através de observação participante realizada na Escola de Líderes da Associação Vitória em Cristo (Eslavec), em Águas de Lindóia, São Paulo, o autor elabora a categoria "hiper- 
convertido" para nomear o processo de construção do pastor pentecostal. Se a conversão diz respeito ao processo de aquisição de uma linguagem religiosa específica, o que o autor revela nesse quinto artigo do dossiê são as interfaces entre linguagem, materialidade e experiência, dispostas normativamente por uma ideologia semiótica pentecostal na conformação do pastor. Este sujeito, elevado sobre os demais pela vocação que lhe pertenceria, deve manter uma exemplaridade por meio da manipulação de mecanismos e técnicas corporais e de uso da linguagem com vistas a, de uma só vez, inspirar e manter-se em posição de autoridade religiosa. Busca comprovar, através desta investigação, que o pentecostalismo se afina à modernidade por procedimentos de mediação a ela identificados.

No último artigo do dossiê, intitulado "Entre a sepultura e a cadeia: um olhar etnográfico sobre a conversão religiosa de usuários de crack em São Paulo", Debora Fromm apresenta aos leitores de Religião \& Sociedade resultados de uma pesquisa etnográfica realizada entre 2011 e 2015 na região conhecida como cracolândia, no centro de São Paulo (SP). Em especial, a autora analisa a trajetória de um ex-usuário de crack que se torna missionário da Missão Batista Cristolândia. No contexto de vida dos atores acompanhados em campo, marcados por grande vulnerabilidade social, violência e insegurança, a conversão religiosa é considerada uma alternativa potencial à morte e à prisão. Nesse sentido, ela emerge como meio de redenção material, moral, emocional, ontológica, enfim. O caso de Edu, tratado no artigo, conforma uma experiência de sucesso da ação missionária batista que mereceu destaque no Programa Seja Luz, da Junta de Missões Nacionais, da Convenção Batista Brasileira (CBB), em seu canal no YouTube. A apresentação da conversão e da vida de conquistas que se segue são enfatizadas como meio de mostrar a força da ação missionária da igreja e dos valores por ela defendidos, assim como a eficácia dessa estratégia de "sobrevivência na adversidade". Nesse sentido, o uso adequado de códigos e a circulação precisa entre fronteiras ganha relevo analítico nessa reflexão sobre a conversão religiosa.

\section{Referências Bibliográficas}

ABUMANSSUR, Edin. (2014), "Fé e crime na quebrada: pentecostais e PCC na construção da sociabilidade nas periferias de São Paulo (Faith and crime in the 'quebrada': Pentecostalism and PCC in the construction of sociability in the outskirts of São Paulo)". Horizonte: Revista de Estudos de Teologia e Ciências da Religião (Online), v. 12, p. 99-120.

BIRMAN, Patrícia. (1996), "Cultos de Possessão e Pentecostalismo no Brasil: Passagens". Religião e Sociedade, $17(1-2): 90-109$.

BIRMAN, Patrícia e MACHADO, Carly. (2011), "A violência dos justos: evangélicos, mídia e periferias da metrópole". RBCS, vol. 27, n 80: 55-69.

COMAROFF, Jean; COMAROFF, John. (1991), Revelation and Revolution: Christianity, Colonialism and Consciousness in South Africa. vol. 1. Chicago: University of Chicaco Press.

CAMPOS, Leonildo Silveira. (2006), "De políticas de Cristo: uma análise do comportamento político de protestantes históricos e pentecostais no Brasil”. In: J. Burity \& M. d. C. Machado (orgs.). Os votos 
de Deus: evangélicos, política e eleições no Brasil. Massangana, pp. 29-90

CAMPOS, Roberta Bivar; REESINK, Mísia Lins. (2011), "Mudando de eixo e invertando o mapa: para uma antropologia da religião plural”. Religião e Sociedade, 31(1): 209-227, 2011

CONTINS, Marcia. Tornando-se pentecostal: um estudo comparativo sobre pentecostais negros nos Estados Unidos e no Brasil. Tese de Doutorado, ECO/UFRJ, 1995.

CORRÊA, Diogo. (2015), Anjos de Fuzil: Uma Etnografia da Relação entre Igreja e Tráfico na Cidade de Deus. Rio de Janeiro: Tese de Doutorado: Universidade do Estado do Rio de Janeiro (UERJ).

CÔRTES, Mariana. (2007), O bandido que virou pregador. São Paulo: Hucitec.

CÔRTES, Mariana. (2017), Diabo e fluoxetina: pentecostalismo e psiquiatria na gestão da diferença. Curitiba: Appris.

DIAS, Camila. (2008), A Igreja como refúgio e a Bíblia como esconderijo: religião e violência na prisão. São Paulo: Humanitas.

DUARTE, Luiz Fernando; GIUMBELLI, Emerson. (1995), "As concepções cristã e moderna da pessoa: paradoxos de uma continuidade”. Anuário Antropológico/93 Rio de Janeiro: Tempo Brasileiro.

DULLO, Eduardo. 2013. A produção de subjetividades democráticas e a formação do secular no Brasil a partir da pedagogia de Paulo Freire. Rio de Janeiro: Tese de Doutorado, Universidade Federal do Rio de Janeiro (UFRJ).

ENGELKE, Mathew. (2004), "Discontinuity and the Discourse of Conversion". Journal of Religion in Africa, vol. 34, fasc. 1/2 (Feb. - May, 2004), p. 82-109.

FRESTON, Paul. (1994), "Breve história do pentecostalismo brasileiro". In: A. Antoniazzi et al. Nem anjos nem demônios: interpretações sociológicas do pentecostalismo. Petrópolis: Vozes.

FRESTON, Paul. (1993), Protestantes e Política no Brasil: da constituinte ao impeachment. Campinas: Tese de Doutorado, Unicamp.

GUSMÃO, Eduardo Henrique Araújo de. (2011), Dinâmicas prisionais e religião: uma análise sobre as trajetórias e experiências de detentos em processos de conversão. Recife: Tese de Doutorado em Antropologia, Universidade Federal de Pernambuco.

HEIRICH, Max. (1977), "Change of Heart: A Test of Some Widely Theories about Religious Conversion”. American Journal of Sociology, 83(3):653- 680.

HERVIEU-LÉGER, Danièle. ([1999]2008), O peregrino e o convertido: a religião em movimento. Petrópolis: Vozes.

HORTON, Robin. (1971), "African Conversion”. Africa 41: 85-108.

LIMA, Diana N. O. (2008), Sujeitos e objetos do sucesso: antropologia do Brasil emergente. Rio de Janeiro, Garamond.

LINS, Paulo e LOURDES DA SILVA, Maria de. (1990), "Bandidos e evangélicos: extremos que se tocam". Religião e Sociedade, vol. 15, no 1: 166-173.

LOBO, Edileuza Santana. (2002), Igrejas atrás das Grades: um estudo sobre a atuação de católicos e evangélicos no sistema penitenciário do Rio de Janeiro. Rio de Janeiro: IFCS-UFRJ, Dissertação de mestrado.

LOFLAND, John e STARK, Rodney. (1965), "Becoming a World-Saver: A Theory of Conversion to a Deviant Perspective”. American Sociological Review, vol. 30, no 6, p. 862-875.

LOPES, Natânia. (2017), "Prostituição sagrada e a prostituta como objeto preferencial de conversão dos "crentes". Religião e Sociedade, vol. 37, no 1, p. 34-46.

MACHADO, Maria. das Dores Campos (2013), "Conversão religiosa e a opção pela heterossexualidade em tempos de aids: notas de uma pesquisa". Cadernos Pagu, no 11, p. 275-301.

MACHADO, Maria das Dores Campos \& BURITY, Joanildo. (2014), "A ascensão política dos pentecostais no Brasil na avaliação de líderes religiosos". Dados, 3 (57): 601-631.

MACHADO, Carly. (2014), "Pentecostalismo e o sofrimento do (ex-)bandido: testemunhos, mediações, modos de subjetivação e projetos de cidadania nas periferias". Horizontes Antropológicos, ano 20, $\mathrm{n}^{\circ}$ 42: $153-180$.

MAFRA, Clara. (1998), "Drogas e símbolos: redes de solidariedade em contextos de violência”. In: A. 
Zaluar; M. Alvito (Org.). Um século de favela. Rio de Janeiro: FGV.

MAFRA, Clara. (2002), Na posse da palavra: religião, conversão e liberdade pessoal em dois contextos nacionais. Lisboa: ICS.

MARIANO, Ricardo. (2005), Neopentecostais: Sociologia do Novo Pentecostalismo no Brasil. São Paulo: Edições Loyola.

MARIANO, Ricardo. (2013), “Mudanças no campo religioso brasileiro no Censo 2010”. Debates do NER, no 24, p. 119-137.

MARIZ, Cecília. (1991), "A religião e o enfrentamento da pobreza no Brasil”. Revista Crítica de Ciências Sociais. № 33, p. 11-24.

MARIZ, Cecília; GRACINO Jr., Paulo. (2013), "As igrejas pentecostais no censo de 2010". In: F. Teixeira; R. Menezes, Renata (Org.). Religiões em Movimento: O Censo de 2010. Petrópolis: Vozes.

SILVA, Lucas Medrado da. (2015), "Cristianismo e criminalidade - a adesão de bandidos no universo cristão pentecostal. São Paulo: Fonte Editorial.

SILVA, Luiz Antonio Machado da. (2010), "Violência urbana, segurança pública e favelas: o caso do Rio de Janeiro atual”. Cad. CRH, vol. 23, no 59, p. 283-300.

MESQUITA, Wânia. (2003), Em busca da prosperidade: trabalho e empreendedorismo entre pentecostais. Rio de Janeiro: Tese de Doutorado, Instituto Universitário de Pesquisas do Rio de Janeiro (IUPERJTec).

MESQUITA, Wânia. (2012), Sociabilidade violenta e ordem pentecostal em favelas. Antropolítica, n⿳ํㅡㄴ 33, p. 217-234.

MISSE, Michel. (1999), Malandros, marginais e vagabundos e a acumulação social da violência no Rio de Janeiro. Rio de Janeiro: Tese de Doutorado, Iuperj.

NATIVIDADE, Marcelo Tavares. (2008), Deus me aceita como eu sou? A disputa sobre o significado da homossexualidade entre evangélicos no Brasil. Rio de Janeiro: Tese de Doutorado, PPGSA/UFRJ.

NOVAES, Regina Reyes. (1985), Os Escolhidos de Deus. Rio de Janeiro: ISER.

NOVAES, Regina Reyes. (1998), "Apresentação". In: R. C. Fernandes, et al. Novo nascimento: os evangélicos em casa, na igreja e na política. Rio de Janeiro: Mauad. p. 7-11.

RAMBO, Lewis. (2003), "Anthropology and the study of conversion”. In: A. Buckser; S. Glazier (Org.). The Anthropology of Religious Conversion. Lanham: Rowman \& Littlefield Publishers.

RIBEIRO, Fernanda Mendes Lage; MINAYO, Cecília. (2018), "Sentidos del trabajo religioso en contextos marcados por la violencia: estudio en un complejo de favelas en Río de Janeiro". Salud Colectiva, vol. 14, p. 273-288.

RIVERA, Paulo Barrera. (2016), "Identidades pentecostais e redes de apoio no contexto da. Favela". Agenda Social (UENF), vol. 9, p. 92-104.

ROBBINS, Joel. (2003), "On the Paradoxes of Global Pentecostalism and the Perils of Continuity Thinking". Religion 33: 221-231.

ROLIM, Fernando Cartaxo. (1985), Pentecostais no Brasil: uma interpretação sócio-religiosa. Petrópolis: Editora Vozes.

SCHELIGA, Eva L. (2000), “'E me visitastes quando estive preso' - sobre a conversão religiosa em unidades penais de segurança máxima.” Florianópolis: Dissertação de Mestrado, UFSC.

SCHELIGA Eva Lenita. (2004), "Pesquisando conversão pentecostal em unidades penais". Religião e Sociedade, vol. 24, no 2, p. 73-99.

SCHELIGA Eva Lenita. (2005), "Sob a proteção da Bíblia? A conversão ao pentecostalismo em unidades penais paranaenses". Debates do NER no 8 , ano 6, p. 57-72.

TARGINO, Janine; MESQUITA, Wânia. (2020), "Experiências de conversão em uma comunidade terapêutica religiosa feminina”. Ciencias Sociales y Religión/Ciências Sociais e Religião, vol. 22, e020034.

TAYLOR, Charles. (1997), As fontes do self: a construção da identidade moderna. Rio de Janeiro: Edições Loyola.

TEIXEIRA, Cesar Pinheiro. (2008), "O pentecostalismo em contextos de violência: uma etnografia das relações entre evangélicos pentecostais e traficantes de drogas em Magé”. Ciências Sociais e Religião/ 
Ciências Sociales y Religion, no 10, p. 181-205.

TEIXEIRA, Cesar Pinheiro. (2011), A construção social do "ex-bandido": um estudo sobre sujeição criminal e pentecostalismo. Rio de Janeiro: 7Letras.

TEIXEIRA, Cesar. (2013), A teia do bandido: um estudo sobre bandidos, policiais, evangélicos e agentes sociais. Rio de Janeiro: Tese de Doutorado, PPGSA/IFCS/UFRJ.

TEIXEIRA, Cesar Pinheiro (2016). "O testemunho e a produção de valor moral: observações etnográficas sobre um centro de recuperação evangélico". Religião e Sociedade, 36(2): 107-134.

TEIXEIRA, Cesar Pinheiro; BRANDÃO, Beatriz. (2019), "Sobre as formas sociais da mudança individual: o testemunho em centros de recuperação pentecostais". Anthropológicas, vol. 30, n⿳ 1, p. 136-157.

VITAL DA CUNHA, Christina. (2008), "Traficantes evangélicos: novas formas de experimentação do sagrado em favelas cariocas". Plural, 15, 13-46.

VITAL DA CUNHA, Christina. (2015), "Oração de traficante: uma etnografia". Rio de Janeiro: Garamond.

VITAL DA CUNHA, Christina. (2018), "Pentecostal cultures in urban peripheries: a socioanthropological analysis of Pentecostalism in arts, grammars, crime and morality". Vibrant, vol.15, p.93-115.

VITAL DA CUNHA, Christina. (2014). "Religião e criminalidade: traficantes e evangélicos entre os anos 1980 e 2000 nas favelas cariocas”. Revista Religião e Sociedade, v.34, p.61-93.

ZALUAR, Alba. (1997), "O Crime e a Não-cidadania: Os Males do Brasil”, in P. Birman, R. Novaes e S. Crespo (orgs.), O Mal à Brasileira. Rio de Janeiro, EdUERJ. 


\section{Cesar Pinheiro Teixeira* (cesarpinheiroteixeira@gmail.com)}

* Professor do Programa de Pós-Graduação em Sociologia Política da Universidade de Vila Velha (UVV), Vila Velha, ES, Brasil; Pesquisador do Núcleo de Estudos da Cidadania, Conflito e Violência Urbana (NECVU), Universidade Federal do Rio de Janeiro (UFRJ); Doutor em Sociologia pela UFRJ.

\section{Christina Vital da Cunha** (chrisvita110@gmail.com)}

** Professora associada do Departamento de Sociologia e do Programa de PósGraduação em Sociologia da Universidade Federal Fluminense (UFF), Niterói, Rio de Janeiro, Brasil. Coordena o Laboratório de estudos sócio antropológicos em política, arte e religião (LePar), UFF; Integra a equipe de pesquisadores do MARES - Religião, arte, materialidade, espaço público: grupo de antropologia, Universidade Federal do Rio Grande do Sul (UFRGS). Doutora em Ciências Sociais pela Universidade do Estado do Rio de Janeiro (UERJ).

\section{Diogo Silva Corrêa*** (dioscorrea@gmail.com)}

*** Professor do Programa de Pós-Graduação em Sociologia Política da Universidade de Vila Velha (UVV), Vila Velha, ES, Brasil; Coordenador do Laboratório de Estudos de Teoria e Mudança Social (Labemus), Universidade Federal de Pernambuco (UFPE), Universidade de Vila Velha (UVV); Pesquisador do Centre d'Études des Mouvements Sociaux (CEMS), École des Hautes Études en Sciences Sociales (EHESS), França; Doutor em Sociologia pela EHESS e pelo Instituto de Estudos Sociais e Políticos da Universidade do Estado do Rio de Janeiro (IESP/UERJ).

\section{Lívia Reis**** (liviareisa@gmail.com)}

**** Pesquisadora de pós-doutorado no Programa de Pós-Graduação em Antropologia Social do Museu Nacional da Universidade Federal do Rio de Janeiro, Rio de Janeiro (PPGAS/MN/UFRJ), Rio de Janeiro, RJ, Brasil; Membro do Laboratório de Antropologia do Lúdico e do Sagrado (Ludens) e do Grupo de Pesquisa em Antropologia da Devoção (GPAD), UFRJ; Colaboradora do Instituto de Estudos da Religião (ISER); Doutora em Ciências Sociais pela Universidade do Estado do Rio de Janeiro (UERJ). 
Errata

1) Em relação ao Editorial "Processos de conversão religiosa", DOI https://doi. org/10.1590/0100-85872021v41n1editorial, publicado em Rev. Relig. soc. 41 (1), JanAbr, 2021, pág. 11:

Onde se lia:

Cesar Pinheiro Teixeira

Christina Vital da Cunha

Diogo Silva Corrêa

Lívia Reis

\section{Leia-se:}

Cesar Pinheiro Teixeira

Christina Vital-da-Cunha

Diogo Silva Corrêa

Lívia Reis

2) Ainda em relação ao Editorial "Processos de conversão religiosa", DOI https://doi. org/10.1590/0100-85872021v41n1editorial, publicado em Rev. Relig. soc. 41 (1), JanAbr, 2021, pág. 16:

Onde se lia:

Em "O pastor como hiperconvertido: uma etnografia da constituição do líder pentecostal", Cleonardo Barros apresenta uma perspectiva inovadora em torno dos líderes vocacionados para o exercício de ministração da Bíblia.

\section{Leia-se:}

Em "O pastor como hiperconvertido: uma etnografia da constituição do líder pentecostal", Cleonardo Mauricio-Junior apresenta uma perspectiva inovadora em torno dos líderes vocacionados para o exercício de ministração da Bíblia. 